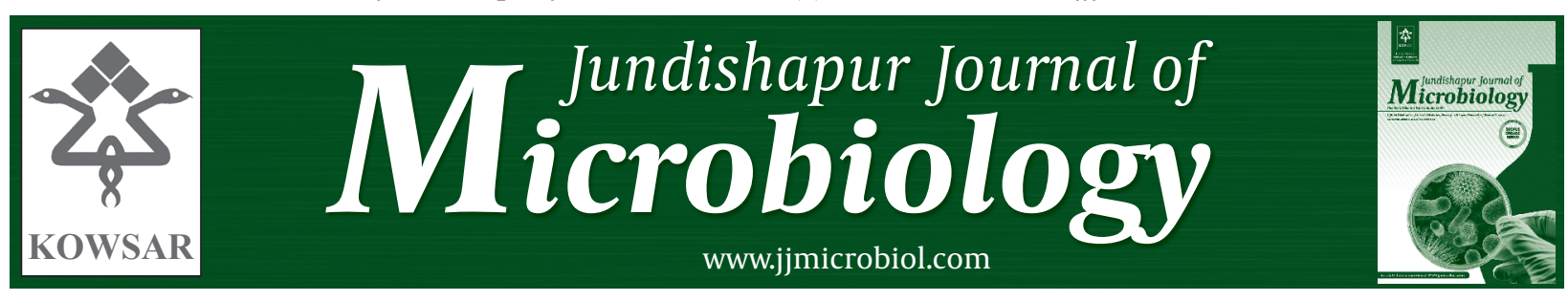

\title{
Prophage Typing of Methicillin Resistant Staphylococcus aureus Isolated from a Tertiary Care Hospital in Tehran, Iran
}

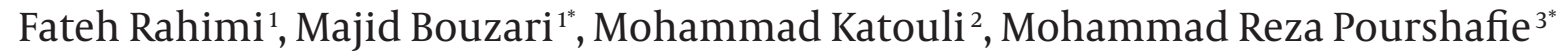 \\ ${ }^{1}$ Department of Biology, Faculty of Science, University of Isfahan, Isfahan, IR Iran \\ ${ }^{2}$ Faculty of Science, Health and Education, University of the Sunshine Coast, Queensland, Australia \\ ${ }^{3}$ Department of Microbiology, Pasteur Institute of Iran, Tehran, IR Iran
}

\section{A R T I C L E I N F O}

Article type:

Original Article

\section{Article history:}

Received: 26 Feb 2012

Revised: 07 May 2012

Accepted: 21 May 2012

Keywords:

Methicillin-Resistant

Staphylococcus aureus

Tehran

\begin{abstract}
A B S T R A C T
Background: Staphylococcus aureus is a common cause of infections among humans and animals and it is known as a community-acquired and nosocomial pathogen. Most of the isolates contain lysogenic phages which are responsible for production of various virulence factors such as enterotoxins, staphylokinase, $\beta$-lysin, lipase, exfoliative toxin A and Pantone-vlaentine leukociden (PVL). All staphylococcus isolates are classified in 6 groups according to their sensitivity to 27 known lysogenic phages.

Objectives: This study was performed to detect the presence of bacteriophage types and determine antibiotic resistance pattern of methicillin resistant S. aureus (MRSA) isolates obtained from a tertiary care hospital in Tehran, Iran from 2008 to 2010.

Materials and Methods: A total of 968 S. aureus isolates were collected from a tertiary care hospital in Tehran, Iran and identified at the species level by PCR and biochemical tests. Susceptibility to 17 antibiotics was determined. Then oxacillin and vancomycin minimum inhibitory concentration (MIC) of the resistant isolates were determined. Multiplex-PCR was used to detect 6 classes of prophages.

Results: Out of the 968 isolates 247 isolates were resistant to methicillin. Highest antibiotic resistance was seen to penicillin (100\%), erythromycin (89.8\%), kanamycin (89.4\%), ciprofloxacin (88.6\%) and tobramycin (87.4) respectively. None of the MRSA isolates showed resistance to vancomycin, synercid and linezolid. MIC results indicated that 46.1 and $4.4 \%$ of isolates with high (MIC $\geq 128 \mu \mathrm{g} / \mathrm{ml}$ ) and low level (MIC $\geq 4 \mu \mathrm{g} / \mathrm{ml}$ ) showed resistance to oxacillin, respectively. Four different phage types and eight patterns of prophages were detected. All MRSA isolates contained at least one prophage. Totally, 2.8, 69.2 and $27.9 \%$ contained 5, 4 and 3 different prophage types, respectively.

Conclusions: High prevalence of different classes of prophages indicating the potential to carry a broad spectrum of virulence factors and high oxacillin resistance were found in the MRSA isolates. Detection of SGF phage in $100 \%$ of the isolates indicates the ability of these isolates to produce virulence factors.
\end{abstract}

Published by Kowsar Corp, 2013. cc 3.0.

Implication for health policy/practice/research/medical education:

This study has highlighted the presence of bacteriophage types among MRSA isolates to show the high potential of these isolates to produce broad spectrum of virulence factors.

\section{- Please cite this paper as:}

Rahimi F, Bouzari M, Katouli M, Pourshafie MR. Prophage Typing of Methicillin Resistant Staphylococcus aureus Isolated from a Tertiary Care Hospital in Tehran, Iran. Jundishapur J Microbiol. 2013;6(1):80-5. DOI: 10.5812/jjm.4616

\footnotetext{
* Corresponding author: Majid Bouzari, Department of Biology, Faculty of Science, University of Isfahan, Hezarjereeb Street, Isfahan 81746-73441,IR Iran. Tel:+983117932459, Fax:+98-3117932456. E-mail: bouzari@sci.ui.ac.ir

Mohammad Reza Pourshafie, Department of Microbiology, Pasteur Institute of Iran, Tehran, 13164, IR Iran. Tel/ Fax:+98-2166405535. E-mail: pour@pasteur.ac.ir DOI:10.5812/jjm.4616

(C) 2013 Ahvaz Jundishapur University of Medical Sciences; Published by Kowsar Corp.

This is an Open Access article distributed under the terms of the Creative Commons Attribution License (http://creativecommons.org/licenses/by/3.0), which permits unrestricted use, distribution, and reproduction in any medium, provided the original work is properly cited.
} 


\section{Background}

Staphylococcus aureus is an important human nosocomial pathogen that can cause a variety of skin infections and toxin-mediated diseases including gastroenteritis, staphylococcal scalded-skin syndrome, staphylococcal food poisoning and toxic shock syndrome (1). Whilst the use of antibiotics can kill most strains of pathogenic microbes, the increase of multiple drug resistant $S$. aureus, especially among hospital patients has been a worrying trend. Not only are some strains resistant to oxacillin owing to the acquisition of the staphylococcal cassette chromosome mec (SCC mec) element, but also the species as a whole has increased its virulence and transmissibility $(2,3)$.

Horizontal gene transfer plays an extremely important role in bacterial evolution. It has been estimated that some $20 \%$ of the extant genetic content of any given bacterial species has been acquired from other organisms by means of mobile genetic elements (MGE) such as bacteriophages, insertion sequences (IS), plasmids, and transposons (3-5).

Bacteriophages through horizontal gene transfer and lysogenic phage conversion can convert a non-virlulent strain of staphylococcus to a virulent strain (6). Prophage incorporation into the $S$. aureus results in increased ability of the bacteria to colonize the host tissue by ecological adaptation to human host, evasion from the immune system and production of virulence factors $(5,7)$. A posa sible contributor to this increased virulence is PantonValentine leukocidin (PVL), the prophage-encoded toxin responsible for necrotizing pneumonitis, which can be fatal within 24-48 hours, as recently described. Superantigens are among the other important staphylococcal virulence factors; they are responsible for food poisoning, toxic shock syndrome (TSS) and necrotizing fasciitis (7).

For many years phage typing was the suggested method for typing of $S$. aureus isolates with more than 250 staphylococcal phages described $(8,9)$. Temperate phages of $S$. aureus were classified into six phage types on the basis of their lytic activity, morphology and serological properties. These phages $(10,11)$ including 3A (SGA), 11 (SGB), 77 (SGF) (77a and 77b) (SGFa and SGFb) and 187 (SGL) are implicated on human diseases $(5,8)$.

\section{Objectives}

The current study aimed to identify and characterize the presence of different bacteriophage types among MRSA strains isolated from a tertiary care hospital in Tehran, Iran. Also, the antibiotic resistance patterns of these isolates were reported.

\section{Materials and Methods}

\subsection{Sample Collection}

Nine hundred and sixty eight isolates of S. aureus were collected during April 2008 to November 2010 from a tertiary care hospital located in center of Tehran. 63\% and 37\% of S. aureus strains were isolated from outpatients and inpatients with staphylococcal infections, respectively.

\subsection{Isolation and Phenotyping of S. aureus}

Identification of the clinical isolates of S. aureus was performed by traditional biochemical tests, including catalase, DNase, coagulase and mannitol fermentation tests, and Gram staining $(12,13)$. S. aureus ATCC 29213 and S. epidermidis ATCC 35984 were used as negative and positive controls. PCR amplification of the nuc gene (14) was performed only for MRSA strains.

\subsection{Antimicrobial Susceptibility Testing}

Susceptibility of all $968 \mathrm{~S}$. aureus isolates to oxacillin $(1 \mu \mathrm{g})$ (Mast Diagnostics, Merseyside, United Kingdom) was determined by disc diffusion method according to the guidelines of Clinical and Laboratory Standards Institute (CLSI) (15). All methicillin resistant strains were collected and MIC of oxacillin and vancomycin was determined by Etest (AB, Biomerieux, Marcy l'Etoile, France) within a concentration range of 0.016 to $256 \mu \mathrm{g} / \mathrm{ml}$. Isolates that had MIC $\geq 4 \mu \mathrm{g} / \mathrm{mL}$ and MIC $\geq 16 \mu \mathrm{g} / \mathrm{mL}$ were selected as MRSA and vancomycin resistant S. aureus (VRSA) isolates, respectively.

Susceptibility patterns of the MRSA isolates to penicillin $(5 \mu \mathrm{g})$, erythromycin $(15 \mu \mathrm{g})$, kanamycin $(30 \mu \mathrm{g})$, ciprofloxacin $(30 \mu \mathrm{g})$, amikacin $(30 \mu \mathrm{g})$, minocycline (30 $\mu \mathrm{g})$, fusidic acid $(10 \mu \mathrm{g})$, clindamycin $(2 \mu \mathrm{g})$, tobramycin $(10 \mu \mathrm{g})$, rifampicin $(2 \mu \mathrm{g})$, nitrofurantoin $(50 \mu \mathrm{g})$, sulphamethoxazole-trimethoprime $(1.25-23.75 \mu \mathrm{g})$, linezolid (10 $\mu \mathrm{g})$, synercid (15 $\mu \mathrm{g})$, chloramphenicol $(30 \mu \mathrm{g})$, gentamicin $(10 \mu \mathrm{g})$ and tetracycline $(30 \mu \mathrm{g})$ were determined by disc diffusion method according to the guidelines of CLSI (15). The antibiotic discs were purchased from Mast Diagnostics (Merseyside, United Kingdom).

\subsection{DNA Extraction}

DNA extraction was done by High Pure PCR Template Preparation Kit (Roche, Mannheim, Germany) according to the instructions of the manufacturer with some modifications. The concentrations of all extracted DNAs were determined by Nanodrop 1000 machine (NanoDrop, Wilmington, USA). One micro liter of each DNA was used as template in PCR reaction.

\section{5. $P C R$}

PCR primers specific for S. aureus nuc gene (14) were synthesized by Tib-Molbiol (Berlin, Germany). the PCR mixture contained 10X PCR buffer, taq DNA polymerase (0.5 U) (HT Biotechnology, Cambridge, United Kingdom), each primer $(1.6 \mu \mathrm{M}), \mathrm{MgCl}_{2}(1.2 \mu \mathrm{M})$ and each $\mathrm{dNTP}(0.64$ $\mu \mathrm{M})$. The PCR cycles were as follows: an initial denatur- 
ation at $94^{\circ} \mathrm{C}$ for $5 \mathrm{~min}$, with 30 cycles of denaturation at $94^{\circ} \mathrm{C}$ for $45 \mathrm{~s}$, annealing at $62^{\circ} \mathrm{C}$ for $45 \mathrm{~s}$ and elongation at $72^{\circ} \mathrm{C}$ for $1 \mathrm{~min}$ and $45 \mathrm{~s}$ and final extension at $72^{\circ} \mathrm{C}$ for $8 \mathrm{~min}$ (14). PCR products were electrophoresed on a $1.5 \%$ agarose gel in a $0.5 \mathrm{X}$ Tris-Borate-EDTA (TBE) buffer and stained in ethidium bromide.

\subsection{Multiplex and Individual PCR for Identification of Bacteriophages}

According to the protocol and primers published by Pantucek and colleagues (8), a multiplex-PCR reaction was mixed in a volume of $25 \mu \mathrm{l}$ consisting of $2 \mu \mathrm{l}$ of template DNA, 10X PCR buffer, taq DNA polymerase (1 U), each primer $(0.4 \mu \mathrm{M})(\mathrm{SGA1} / \mathrm{SGA} 2, \mathrm{SGB} 1 / \mathrm{SGB} 2, \mathrm{SGD} 1 / \mathrm{SGD} 2$, SGL1/SGL2, SGFb1/SGFb2 and SGFa1/SGFa2), $\operatorname{MgCl}_{2}(0.8 \mu \mathrm{M})$ and dNTP mix $(100 \mu \mathrm{M})$. Each reaction mixture was then loaded into a thermal cycler for initial denaturation (5 min, $94^{\circ} \mathrm{C}$ ) and 30 cycles of amplification consisting of denaturation $\left(1 \mathrm{~min}, 94^{\circ} \mathrm{C}\right)$, annealing $\left(1.5 \mathrm{~min}, 57^{\circ} \mathrm{C}\right)$, and chain extension $\left(1.5 \mathrm{~min}, 70^{\circ} \mathrm{C}\right)$. Amplification was once again followed by a final chain extension cycle $(3 \mathrm{~min}$, $70^{\circ} \mathrm{C}$ ). Then, $8 \mu \mathrm{l}$ of PCR product and $2 \mu \mathrm{l}$ of $5 \mathrm{X}$ loading buffer were electerophoresed in a 1.5\% agarose gel for 1 hour at $90 \mathrm{~V}$ in $0.5 \mathrm{X}$ TBE buffer.

Whenever a multiplex-PCR did not result in amplification, single PCR reaction was performed with each set of the primers. The following mixture was then used in the single PCR reaction containing $25 \mu$ of $1 \mu$ l template DNA, 10X PCR buffer, taq DNA polymerase (0.5 U), each set of primers alone $(0.3 \mu \mathrm{M})$ (SGA1/SGA2, SGB1/SGB2, SGD1/ SGD2, SGL1/SGL2, SGFb1/SGFb2 and SGFa1/SGFa2), $\mathrm{MgCl}_{2}$ $(0.6 \mu \mathrm{M})$ and dNTP mix $(50 \mu \mathrm{M})$. Electerophoresis process was the same as described for multiplex-PCR.

\section{Results}

Totally, all suspected isolates gathered from a tertiary care hospital were confirmed as S. aureus by standard biochemical tests. Out of 968 confirmed S. aureus, 247 (25.5\%) were selected as MRSA and analyzed more. As indicated in Table 1, the highest antimicrobial resistance was shown to penicillin, erythromycin, kanamycin, ciprofloxacin, tobramycin, clindamycin, tetracycline and amikacin. All MRSA isolates showed susceptibility to vancomycin, synercid and linezolid, and also more than ninety nine percent of the isolates were susceptible to nitrofurantoin and fusidic acid. Resistance to gentamicin, minocycline, SXT and rifampicin was less than seventy percent. Eleven isolates were susceptible to all antibiotics except penicillin.

E-test showed that all of the isolates were resistant to oxacillin (MIC $\geq 4 \mu \mathrm{g} / \mathrm{mL}$ ) (Table 2), $46.1 \%$ and $4.4 \%$ of the MRSA isolates showed high (MIC $\geq 128 \mu \mathrm{g} / \mathrm{mL}$ ) and low resistance (MIC $\geq 4 \mu \mathrm{g} / \mathrm{mL}$ ) to oxacillin, respectively. The MIC ranges of $49.4 \%$ of MRSA isolates varied from 24 to $96 \mu \mathrm{g} / \mathrm{mL}$.

In the current study all types of prophages could be

\begin{tabular}{ll}
\hline \multicolumn{2}{|l}{ Table 1. Antibiotic Resistance Pattern Among MRSA Isolates. } \\
\hline \multicolumn{1}{|c|}{ Antibiotic Resistance, No. (\%) } \\
\hline Penicillin & $247(100)$ \\
\hline Erythromycin & $222(89.8)$ \\
\hline Kanamycin & $221(89.4)$ \\
\hline Ciprofloxacin & $219(88.6)$ \\
\hline Tobramycin & $216(87.4)$ \\
\hline Clindamycin & $205(82.9)$ \\
\hline Tetracycline & $201(81.3)$ \\
\hline Amikacin & $189(76.5)$ \\
\hline SXT & $171(69.2)$ \\
\hline Rifampicin & $164(66.3)$ \\
\hline Minocycline & $148(59.9)$ \\
\hline Gentamicin & $141(57)$ \\
\hline Nitrofurantoin & $2(0.8)$ \\
\hline Fusidic Acid & $1(0.4)$ \\
\hline Chloramphenicol & $1(0.4)$ \\
\hline Synercid & $0(0)$ \\
\hline Linezolid & $0(0)$ \\
\hline Vancomycin & $0(0)$ \\
\hline
\end{tabular}

\begin{tabular}{|c|c|c|c|c|c|c|c|}
\hline $\begin{array}{l}\text { MIC, } \\
\mu \mathrm{g} / \mathrm{mL}\end{array}$ & 256 & 128 & 96 & 64 & 32 & 24 & 4 \\
\hline No.(\%) & $\begin{array}{l}69 \\
(27.9)\end{array}$ & $\begin{array}{l}45 \\
(18.2)\end{array}$ & $\begin{array}{l}54 \\
(21.9 \%)\end{array}$ & $\begin{array}{l}22 \\
(8.9)\end{array}$ & $\begin{array}{l}17 \\
(6.9 \%)\end{array}$ & $\begin{array}{l}29 \\
(11.7)\end{array}$ & $\begin{array}{l}11 \\
(4.4)\end{array}$ \\
\hline
\end{tabular}

detected by single PCR reactions, except Twort-like (SGD) and SGL,. SGA, SGB, SGF, SGFa and SGFb proghage genes were detected in 11 (4.4\%), 174 (70.4\%), 247 (100\%), 247 (100\%) and 247 (100\%) of the cases, respectively (Figure 1).

Multiplex-PCR reaction including SGA, SGB and SGF

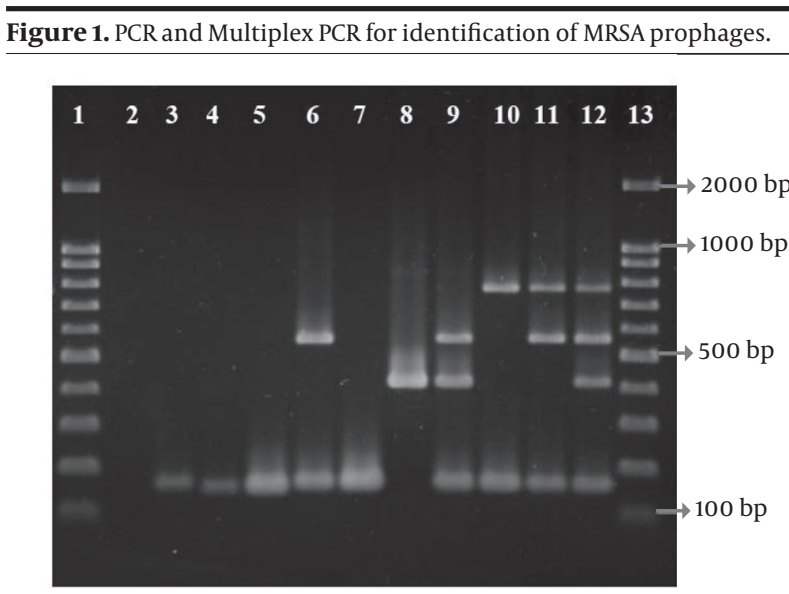

Lanes 1 and 13, 3000 bp DNA ladder (Metabion, Germany). Lane 2: non template control (NTC); Lines 3,7: SGF serogroup; Lane 4,5: SGFb serogroup; Lane 8: SGB serogroup; 6: SGB serogroup; and 7: SGA serogroup). Lanes 6 and 9-12 show the results of multiplex-PCR for the same serogroups. 
prophage sero-groups and sub-group SGFa was amplified successfully. Moreover, addition of primers to detect SGFb resulted in no amplified products of SGF prophages' genome in a multiplex PCR reaction (Table 3). PCR reaction showed that all isolates contained at least 1 prophage sero-groups and 2 sub-groups. SGF serotype was present in $100 \%$ of the MRSA isolates, also SGFa and SGFb were the dominant (100\%) sub-types among the isolates. According to the types of the prophage, 4 different patterns were identified among 247 MRSA isolates. Pattern 3 was the predominant pattern (67.6\%) among MRSA isolates. Pattern 4 with SGF prophage and its two sub-groups constituted $27.9 \%$ of the isolates. Lowest frequency of phages were SGA (4.4\%) and pattern 2 including SGA, SGF, SGFa and SGFb with $1.6 \%$ of the isolates.

All MRSA contained SGA prophage type (4.4\%) showed

Table 3. Different Prophage Patterns and Their Frequency Among MRSA Isolates

\begin{tabular}{llllllll}
\hline $\begin{array}{l}\text { Phage } \\
\text { Patterns }\end{array}$ & \multicolumn{4}{c}{ Phage Types } & \multicolumn{3}{c}{$\begin{array}{l}\text { Frequency, } \\
\text { No.(\%) }\end{array}$} \\
\cline { 2 - 7 } & SGA & SGB & SGF & SGFa & SGFb \\
\hline $\mathbf{1}$ & + & + & + & + & + & $7(2.8)$ \\
$\mathbf{2}$ & + & - & + & + & + & $4(1.6)$ \\
$\mathbf{3}$ & - & + & + & + & + & $167(67.6)$ \\
$\mathbf{4}$ & - & - & + & + & + & $69(27.9)$ \\
\hline
\end{tabular}

resistance only to penicillin and 1 isolate with prophage pattern 3 were resistance to all antibiotics except vancomycin, synercid and linezolid.

\section{Discussion}

The current study results indicated that the frequency of MRSA strains in this hospital was $25.5 \%$. This frequency rate was lower than other MRSA prevalence reports in Iran (16-18). It might be due to higher number of outpatient samples in comparison to inpatient samples in this hospital. In another study in Iran, the prevalence of MRSA isolates was lower than this study (19). Moreover, the reason for the differences in MRSA isolates in different cities and hospitals in Iran could be due to geographical locations, population, method and technical reasons and antibiotic usage in Iran.

Here, it was found that more than eighty percent of MRSA isolates showed resistance to erythromycin, kanamycin, ciprofloxacin, tobramycin, clindamycin and tetracycline. Similarly, Fatholahzade et al. found that more than $90 \%$ of MRSA isolates were resistant to kanamycin, erythromycin, tetracycline and ciprofloxacin (16). Also, Rahimi et al. showed that more than 90\% of MRSA isolates were resistant to penicillin, ciprofloxacin, tobramycin, kanamycin and erythromycin (19). High usage of penicillin and other antibiotics to treat staphylococcal infections in Iran for many years resulted in high rate of resistance among MRSA isolates in this study.
This study showed that resistance to linezolid, synercid and chloramphenicol is low and they are most effective antibiotics against MRSA isolates. This may be due to low consumption of these antibiotics in Iran. This could, in turn, suggest lack of horizontal transfer of resistant genes from other bacterial species to MRSA. Although chloramphenicol is a very effective antibiotic against MRSA isolates in vitro, its prescription is influenced by different side effects, a fact that could explain low resistance frequency $(16,17,19)$. Although linezolid and synercid are most effective antibiotics against MRSA isolates but their high cost limits their consumption for treatment purposes. Similarly, Fatholahzade et al. and Rahimi et al. found no resistance to linezolid and synercid against MRSA isolates in Iran $(16,19)$.

Vancomycin is the last resort and drug of choice to treat infections caused by MRSA isolates in the world, so the emergence of resistance to vancomycin could be an urgent warning for public health. Anyway, these results were inconsistent with other studies in Iran which have reported high prevalence (7\%) of VRSA isolates (20). This might be due to employment of improper diagnostic methods by them. As it has been recommended by CLSI, the standard methods for vancomycin resistance screening in S. aureus are, Etest, broth dilution and agar dilution; therfore the results of disk diffusion test is not reliable.

The current study results indicated high prevalence of bacteriophages among MRSA isolates in Iran. In the current study 3 sero-types and two sub-types of bacteriophages were detected. Furthermore, all MRSA isolates contained at least one SGF bacteriophage type. Similar to the report by Pantoceck et al. (8) who indicated nine different prophages patterns amongst their MRSA isolates in Czech Republic, 5 patterns were detected in Iran. Workman et al. have also reported 10 prophage types among $S$. aureus isolates in seawater in US (21). On the other hand, in contrast to the current study, Pantoceck reported high prevalence of SGA phages. In addition, the presence of triple lysogenic prophages (SGB, SGFa and SGFb) was the dominant pattern in current study MRSA with $67.6 \%$ of the isolates. In contrast to Workman's report who identified the prevalence of triple lysogenic phages to be 3.3\% (21). The difference between the report presented here and the others could be due to different geographical locations where the samples were obtained $(8,21)$.

In this study 5 prophage patterns were detected among MRSA isolates consisting of 3 serotypes and 2 sub-types. All isolates contained two SGB and SGF bacteriophage types. The number of prophage patterns in S. aureus is almost different from other cases reported by several investigators worldwide. Rahimi et al. (19) in Iran, Pantuceck et al. (8) in Czech Republic and Workman et al.(21) in USA have reported 8,9 and 10 prophage patterns among their S. aureus isolates respectively. However, different domi- 
nated phage patterns have been reported by these investigators. Rahimi et al. (19), reported SGFa prophage type among MRSA isolates in Iran. Pantuceck et al. (8) reported SGFA whereas Workman et al. (21) reported SGFa and SGA prophage types. Here, a unique prevalence of SGF, SGFa and SGFb prophage patterns were found which constituted $100 \%$ of the isolates. The differences in phage patterns in these studies could be, in part, due to different geographical locations where these studies were performed.

The double lysogenic (SGB and SGF) and the two subtypes (SGFa and SGFb) of prophages have shown to be associated with production of a broad spectrum of virulence factors $(4,19)$. In the current study the ability of the isolates to produce these virulence factors were not investigated, and therefore the pathogenic properties of the isolates associated with this unique pattern can not be fully confirmed.

The triple lysogenic and the two sub-types of prophages have been shown to be associated with production of a broad spectrum of virulence factors $(4,5)$. The isolates containing pattern 1 are capable of producing different enterotoxins, PVL, TSST and exfoliative toxin. There are conflicting reports on the presence of SGL prophages in S. aureus. The current study results indicated no 187-like prophage in S. aureus, whereas $30 \%$ of the isolates in US contained this prophage. It is also similar to findings of Rahimi et al. and Pantucek et al. that could not isolate any SGL prophage in Iran and Czech Republic. The significance of this prophage in the pathogenicity of $S$. aureus has not yet been shown $(5,22)$.

The frequency of SGA prophages has shown to be from 1 to $93 \%$ in S. aureus isolated from different countries (8, $19,21)$. The present report indicated the frequency of SGA to be $4.4 \%$. PVL, is one of the most important virulence factors and a marker for SCCmec type 2, which has been shown to be associated with SGA phages $(19,23)$.

In conclusion, different prophage types among MRSA isolates have been determined in Tehran. Furthermore, high diversity of bacteriophages among the MRSA isolates in this hospitalare suggesting the high potential of these isolates to produce wide range of virulence factors threatening public health in Tehran.

\section{Acknowledgments}

Authors would like to thank Dr. Ali Jarallahi and Mrs. Banafasheh Parshad for providing the isolates.

\section{Financial Disclosure}

None declared.

\section{Funding/Support}

This research funded, in part, by an operating grant of the Dean of Research and Graduate Studies at the University of Isfahan, and a grant from Ministry of Health of
Iran, Deputy of research and innovation.

\section{Authors' Contribution}

None declared.

\section{References}

1. Gordon RJ, Lowy FD. Pathogenesis of methicillin-resistant Staphylococcus aureus infection. Clin Infect Dis. 2008;46 (Suppl 5):S350-9.

2. Katayama Y, Ito T, Hiramatsu K. A new class of genetic element, staphylococcus cassette chromosome mec, encodes methicillin resistance in Staphylococcus aureus. Antimicrob Agents Chemother. 2000;44(6):1549-55.

3. Novick RP, Christie GE, Penades JR. The phage-related chromosomal islands of Gram-positive bacteria. Nat Rev Microbiol. 2010;8(8):541-51.

4. Malachowa N, DeLeo FR. Mobile genetic elements of Staphylococcus aureus. Cell Mol Life Sci. 2010;67(18):3057-71.

5. Wilson BA, Salyers AA. Is the evolution of bacterial pathogens an out-of-body experience? Trends Microbiol. 2003;11(8):347-50.

6. Boyd EF, Brussow H. Common themes among bacteriophage-encoded virulence factors and diversity among the bacteriophages involved. Trends Microbiol. 2002;10(11):521-9.

7. Vojtov N, Ross HF, Novick RP. Global repression of exotoxin synthesis by staphylococcal superantigens. Proc Natl Acad Sci USA 2002;99(15):10102-7.

8. Pantucek R, Doskar J, Ruzickova V, Kasparek P, Oracova E, Kvardova $\mathrm{V}$, et al. Identification of bacteriophage types and their carriage in Staphylococcus aureus. Arch Virol. 2004;149(9):1689-703.

9. van Belkum A, Tassios PT, Dijkshoorn L, Haeggman S, Cookson B, Fry NK, et al. Guidelines for the validation and application of typing methods for use in bacterial epidemiology. Clin Microbiol Infect. 2007;13 (Suppl 3):1-46.

10. Brussow H, Desiere F. Comparative phage genomics and the evolution of Siphoviridae: insights from dairy phages. Mol Microbiol. 2001;39(2):213-22.

11. Goerke C, Pantucek R, Holtfreter S, Schulte B, Zink M, Grumann D, et al. Diversity of prophages in dominant Staphylococcus aureus clonal lineages. J Bacteriol. 2009;191(11):3462-8.

12. Kateete DP, Kimani CN, Katabazi FA, Okeng A, Okee MS, Nanteza A, et al. Identification of Staphylococcus aureus: DNase and Mannitol salt agar improve the efficiency of the tube coagulase test. Ann Clin Microbiol Antimicrob. 2010;9:23.

13. Saha B, Singh AK, Ghosh A, Bal M. Identification and characterization of a vancomycin-resistant Staphylococcus aureus isolated from Kolkata (South Asia). J Med Microbiol. 2008;57(Pt 1):72-9.

14. Zouharova M, Rysanek D. Multiplex PCR and RPLA Identification of Staphylococcus aureus enterotoxigenic strains from bulk tank milk. Zoonoses Public Health. 2008;55(6):313-9.

15. Watts JL. Performance standards for antimicrobial disk and dilution susceptibility tests for bacteria isolated from animals: approved standard. Clinical and Laboratory Standards Institute (CLSI); 2008.

16. Fatholahzadeh B, Emaneini M, Gilbert G, Udo E, Aligholi M, Modarressi MH, et al. Staphylococcal cassette chromosome mec (SCCmec) analysis and antimicrobial susceptibility patterns of methicillin-resistant Staphylococcus aureus (MRSA) isolates in Tehran, Iran. Microb Drug Resist. 2008;14(3):217-20.

17. Japoni A, Alborzi A, Orafa F, Rasouli M, Farshad S. Distribution Patterns of Methicillin Resistance Genes(mecA) in Staphylococcus aureus Isolated from Clinical Specimens. Iran Biomed $J$. 2004;8(4):173-8.

18. Rahimi F, Bouzari M, Maleki Z, Rahimi F. Antibiotic susceptibility pattern among Staphylococcus spp. with emphasis on detection of mecA gene in methicillin resistant Staphylococcus aureus isolates. Iranian J Clin Infect Dis. 2009;4(9).

19. Rahimi F, Bouzari M, Katouli M, Pourshafie MR. Prophage and antibiotic resistance profiles of methicillin-resistant Staphylococcus aureus strains in Iran. Arch Virol. 2012;157(9):1807-11.

20. Vahdani P, Saifi M, Aslani MM, Asarian AA, Sharafi K. Antibiotic re- 
sistant patterns in MRSA isolates from patients admitted in ICU and infectious ward. Tanaffos. 2004;3:37-44.

21. Workman M, Nigro O, Steward G. Identification of Prophages in Coastal Water Isolates of Staphylococcus aureus. J Young Investigat. 2006;15(5):1.

22. Loessner MJ, Gaeng S, Scherer S. Evidence for a holin-like protein gene fully embedded out of frame in the endolysin gene of Staphylococcus aureus bacteriophage 187. J Bacteriol. 1999;181(15):4452-60.

23. Deurenberg RH, Stobberingh EE. The evolution of Staphylococcus aureus. Infect Genet Evol. 2008;8(6):747-63. 